\title{
ESCRITORES ANTE LA PANTALLA: INTERFERENCIAS LITERARIAS EN LUCÍA Y EL SEXO (JULIO MEDEM, 2001)
}

\author{
Clara Cobo Guijarro \\ (Universidad de Santiago de Compostela) \\ claracoboguijarro@gmail.com
}

RESUMEN: Este trabajo explora películas sobre escritores. La presencia de autores (reales o ficticios) y la muestra del proceso literario en la pantalla se han producido desde los orígenes del cine. Así, a lo largo de varias décadas, sugerentes líneas de investigación han sido abiertas en este contexto y serán atendidas en este estudio. Este tipo de personaje también será examinado en el cine español durante la primera década del siglo XXI. Por último, estas reflexiones se complementarán con el análisis de la película Lucía y el sexo, de Julio Medem (2001).

PALABRAS ClAVE: literatura en el cine, biopic literario, escritor en el cine, Lucía y el sexo, Julio Medem.

\section{WRITERS IN FRONT OF SCREEN: LITERARY INTERFERENCES IN LUCÍA Y EL SEXO (JULIO MEDEM, 2001)}

ABSTRACT: This work explores films about writers. The presence of authors (real or fictional) and the display of the literary process on screen have occurred since early cinema. Thus, along several decades, suggestive lines of research have been opened in this context, so these will be atended in this study. This type of character will be also examinated in Spanish Cinema during the first decade of the XXI century. Finally, these reflections will be complemented by the analysis of Julio Medem's Lucía y el sexo (2001).

KEYWORDS: literature whithin film, literary Biopic, writer on film, Lucía y el sexo, Julio Medem.

\section{EL PERSONAJE ESCRITOR}

La presencia de la literatura en el cine se manifiesta desde los orígenes del Séptimo Arte. Aunque la aparición del cinematógrafo fue celebrada principalmente por creadores literarios europeos (Peña Ardid, 1996: 33), esto no quiere decir que no existiera cierta rivalidad entre ambos medios, sobre todo por el miedo de sus respectivos creadores a una mutua contaminación. Aun así, desde sus inicios, el cine tomó prestado del universo literario la puesta en escena teatral y las tramas propias de formatos como el music hall, el melodrama, el folletín e, incluso, la novela realista decimonónica (Peña Ardid, 1996: 35; Pérez Bowie, 2008: 152). Esta tendencia se reproduce en nuestro país con la consolidación del cine sonoro hasta 1960, mediante la apropiación de «los esquemas literarios más tradicionales», que muchos consideraron parte de los «males congénitos de nuestra cinematografía» (Peña Ardid, 1996: 37). En este escenario puede observarse un panorama en el que, durante décadas, muchos escritores colaboraron en el 
cine al mismo tiempo que muchos otros infravaloraban su condición artística. ${ }^{1}$ Con los años, cineastas y teóricos invertirían sus esfuerzos para que el cine fuera considerado un arte autónomo, dotado de un lenguaje específico. Pero la distancia temporal ha permitido que en la actualidad se cuestione «esa explicación excesivamente teleológica y defensora de la autonomía de lo cinematográfico y se opta por considerar el cine como resultado de un proceso de intertextualidad respecto a las otras artes» (Pérez Bowie, 2008: 153). Así, puede afirmarse con José Antonio Pérez Bowie que el concepto de intertextualidad - concretamente la intertextualidad literaria presente en el relato cinematográfico - permite alumbrar algunas claves sobre cómo lo literario puede ser considerado constitutivo de lo fílmico.

Esta se manifiesta por diversas vías. La adaptación cinematográfica de una obra literaria es, a juicio de Pérez Bowie, «el campo donde se manifiesta de modo más evidente» por diversas razones (2008: 154). Pero hay otras alternativas mencionadas por el experto: las relecturas y reelaboración de textos, temas y mitos literarios, o el tratamiento, ya en el plano discursivo, de técnicas narrativas experimentales procedentes de la tradición literaria. También menciona la presencia de algunas referencias manifiestas que, a modo de homenaje, o con el fin de consolidar un significado implícito, pueden aparecer en pantalla (por usar uno de sus ejemplos, basta recordar el ejemplar de Madame Bovary en manos de la protagonista de El valle de Abraham [Manoel de Oliveira, 1996]). Por último, el investigador cita aquella manifestación que articula el objeto de estudio del presente trabajo: el universo literario erigido como tema del filme. Este puede ser abordado desde múltiples puntos de vista:

Tales argumentos pueden girar en torno al mundo de los escritores, de las vicisitudes del proceso de creación o a las penalidades sufridas por el personaje hasta alcanzar el reconocimiento de su labor y revisten, en ocasiones, caracteres de autobiografía explícita o implícita; por aducir algunos ejemplos mencionaré filmes (algunos de ellos adaptaciones de noveles o piezas teatrales previas) como Viaje alrededor de mi cráneo (Gyorgy Revesz, 1969), Providence (Alain Resnais, 1976), Henry Fool (Hal Hartley, 1997), Epílogo (Gonzalo Suárez, 1984), Tierras de penumbra (Richard Attenborough, 1993, sobre las relaciones entre el novelista inglés C. S. Lewis y la poetisa norteamericana Joy Greham), Soñador rebelde (John Ford, 1965; sobre la biografía de Sean O' Casey), Shakespeare in Love (John Madden, 1998), Julia (biografia de Lilian Hellman dirigida por Fred Zinneman en 1977) o El huésped de las tinieblas (biografía de Bécquer, que firmó Antonio del Amo de 1948). En otros casos el argumento se centra en la figura del lector y en su experiencia con los libros como sucede en $L a$ lectora (Michel Deville, 1988), Balzac y la joven costurera china (Dai Sijie, 2002) o Diario de un lector de Shinjuku (Nagisa Oshima, 1969). La historia puede girar asimismo en torno a las especiales relaciones del escritor con un lector especial como sucede en El cartero y Pablo Neruda (Michael Radford, 1995) o en Descubriendo a Forrester (Gus Van Sant, 2000). O, en algunas ocasiones, articularse en torno a una intriga metaficcional en la que el mundo «real» del escritor se confunde con el de la obra que está escribiendo; ejemplos de ello serían Como destruir al más fabuloso agente secreto del mundo (título español de Le magnifique, de Philippe de Broca, 1973), en donde el personaje interpretado por Jean Paul Belmondo se transforma a través de sus

${ }^{1}$ La relación de los escritores con el cine ha sido recientemente abordada por José Luis Sánchez Noriega (2010: 5-23). El profesor de la Universidad Complutense explica que el descontento inicial de estos profesionales ante el séptimo arte cedió el paso a otra generación de autores que dejarán constancia en su obra de su amor por el cine. Sánchez Noriega también se detiene en el examen de la figura del escritor-cineasta. En el marco del cine español, véase el libro de Rafael Utrera Macías (1985). 
fantasías en el espía protagonista de su novela) o La triple muerte del tercer personaje (Helvio Soto, 1980) en la que el escritor se introduce en el mundo de la ficción para salvar a su personaje (2008: 156).

Tras lo expuesto cabe aseverar que la representación en pantalla del acto de escritura, así como la figuración y caracterización de un escritor ficticio, un lector ficticio y/o la mostración de la relación entre ambos han ocupado un sugerente espacio en la filmografía nacional e internacional. Pero además, la puesta en escena del universo literario en el filme puede superar la mera cuestión tematológica y despertar una serie de operaciones discursivas tales como la metaficción o la metalepsis, por no hablar del potencial que adquiere la transtextualidad en estos filmes.

Centrándonos ya en la figura del escritor en el cine, sobre la que versará en buena medida este trabajo, resulta relevante el comentario de algunos aspectos centrales con el fin de esclarecer el tratamiento concedido a este personaje desde el Séptimo Arte. En los últimos tiempos, esta línea de investigación - desatendida en comparación con otros objetivos de los estudios filmoliterarios - ha suscitado un creciente interés. En consonancia se han de subrayar los trabajos Figures de l'écrivain dans le cinéma américain. Itinéraires de la «voix baladeuse» (2001), de Trudy Bolter; The Writer on Film. Screening Literary Authorship (2013), coordinado por Judith Buchanan; y Screening the Author: The Literary Biopic (2019), de Hila Shachar. Por último, aunque se centra en un contexto exclusivamente literario, también es destacable el monográfico que dirige Michael J. Meyer, titulado Literature and the Writer (2004).

En primer lugar, hemos de hacer referencia al biopic literario, formato que ha proliferado en los últimos 25 años especialmente en el cine angloamericano. El biopic (biographical picture) es un género que comenzó a configurarse como tal a partir de los años 40 del siglo pasado. ${ }^{2}$ En el contexto que nos ocupa, dos de las primeras manifestaciones del biopic literario fueron Voltaire (John G. Adolfi, 1933) y The Life of Emile Zola (William Dieterle, 1937). Sin embargo, la presencia de los escritores en pantalla ya acontece en el cine mudo con Shakespeare writing Julius Caesar (1907), película desaparecida de Georges Méliès, y Dickens' London (1924), de Frank Miller \& Harry B. Parkinson (Marcus, 2013: 35-36). Desde entonces, se cuentan por decenas los autores y autoras que han sido objeto de dramatización: William Shakespeare, Virginia Woolf, Juan Ramón Jiménez, Yukio Mishima, San Juan de la Cruz, F. Scott Fitzgerald, Truman Capote, Lord Byron, Charles Dickens, Sylvia Plath, Oscar Wilde, etc. ${ }^{3}$ Tal y como observa Hila Shachar, aunque el relato biográfico de los literatos ha estado

${ }^{2}$ Véase el estudio de Sánchez Noriega sobre biografía fílmica (biopic) en el cine español (20002010). En las primeras páginas, el autor establece el estado de la cuestión y aporta un interesante discurso teórico y numerosos ejemplos (2012: 57-63). En palabras de Noriega, «la cautela a la hora de establecer el valor historiográfico de la biografía escrita se incrementa con una práctica de la biografía fílmica - biopic, acrónimo de biographical picture - tan variada como compleja; un resbaladizo género sobre el que la discusión teórica puede ser interminable [...]. Los límites difusos de este formato o género se han ampliado en los últimos años con la ruptura de la tradicional dicotomía entre cine documental y argumental, que ha dado paso a una fecunda práctica de hibridaciones, de manera que, con mayor propiedad, se habla de cine de no ficción para referirse a formatos tan diversos como el documental de autor, el cine ensayo, el falso documental, el found footage o cine de imágenes recicladas, las películas de cine doméstico y - lo que aquí interesa mucho más - formatos relacionados con la biografía como el autorretrato, los diarios cinematográficos, las autobiografías, los retratos familiares y videoblogs» (2012: 58-59).

${ }^{3}$ Sánchez Noriega ofrece una relación más amplia en Diccionario temático de cine (2004: 183- 
presente a lo largo de la historia del cine, este subgénero está viviendo una edad de oro que merece ser abordada para explorar «its own particular tropes and screen "language"» (2019: 2).

Quizás sea la diversidad de enfoques que atesora la película biográfica el principal estímulo para estudiarla. Por ejemplo, la recientemente estrenada Conociendo a Astrid ([Unga Astrid] Pernille Fischer Christensen, 2018) desentraña la tortuosa juventud de la creadora de Pipi Calzaslargas sin exhibir sus inquietudes literarias. Caso opuesto es aquel de Miss Potter (Chris Noonan, 2006), pues lo extraordinario de esta película es la coexistencia del marco sociohistórico de la autora con el mundo de su imaginación, que cobra vida en el filme. Menos convencional es Mishima: una vida en cuatro capitulos (Mishima: A Life in Four Chapters), sobre Yukio Mishima (Paul Schrader, 1985). La cinta compagina la presentación de episodios vitales del japonés - el blanco y negro de la infancia cede el paso al color apagado que caracteriza sus últimos años - con la visitación plena de lirismo de sus obras más aplaudidas. La cuidada puesta en escena así como la magistral comprensión del espacio narrativo fílmico determinaron que Schrader recibiera el premio a la mejor contribución artística en el Festival de Cannes. Otro paradigma de la experimentación en el seno del biopic literario es Hawl (Rob Epstein \& Jeffrey Friedman, 2010). No exenta de críticas negativas, la película se hace eco de la trayectoria de Allen Ginsberg mediante un delirante juego genérico en el que se hibridan el falso documental o el cine de animación, entre otros.

A pesar de las excepciones (la película anteriormente mencionada es una de ellas), parte de la crítica lamenta la deriva formal y argumental a la que se ha abandonado este tipo de biopic. Existen numerosos ejemplos en los que lo estrictamente literario — e incluso lo biográfico, apunta Sánchez Noriega - se diluye a favor de mostrar la educación sentimental de sus protagonistas (Sánchez Noriega, 2012: 61; Judith Buchanan, 2013: 14-16). De este modo, aspectos tales como la formación literaria, la inspiración, el acto creativo o la soledad de la profesión se perciben someramente en muchas películas biográficas. Esto puede atribuirse a la falta de dinamismo narrativo que estos motivos ofrecen, pero las verdaderas razones no siguen esa dirección. Geoffrey Wall atribuye esta predisposición a la mera satisfacción de las necesidades de la industria, hasta el punto de que «literary autorship, as conventionally imagined on-screen, has perhaps become our modern version of pastoral» (2013: 133). De hecho, tal y como observa Buchanan, se ha confirmado una tendencia por la que el recurso del autor dramatizado permite explorar el drama romántico. Las experiencias de estos (generalmente jóvenes) escritores no sirven tanto para examinar su biografía con rigor, como para mostrar un tópico cada vez más recurrente: vivir a través de las ficciones que escriben lo que la realidad les niega (2013: 14). Este es el caso de $L a$ joven Jane Austen ([Becoming Jane] Julian Jarrold, 2007) o la premiada Shakespeare enamorado ([Shakespeare in love] John Madden, 1998) (Cartmell, 2013: 155-156). Sin embargo, a pesar del peso que adquieren las tramas amorosas, estas películas albergan otras posibilidades que más tarde exploraremos. ${ }^{4}$

Este rápido apunte sobre el biopic literario nos ha permitido aproximarnos a la figura del autor real dramatizado, pero el autor ficticio también ha tenido una presencia

${ }^{4}$ Sobre la actualidad del biopic literario remitimos al exhaustivo estudio de Shachar (2019) mencionado anteriormente. Este indaga sobre otros aspectos que por razones de espacio no pueden ser tratados en este trabajo. 
destacable. ${ }^{5}$ Tomando como referencia el cine norteamericano y, en especial, el cine clásico de Hollywood, Bolter establece varios tipos a lo largo de un extenso libro utilizando ejemplos de escritores ficticios no referenciales (aunque para casos específicos cita ejemplos de autores reales dramatizados como los anteriormente mencionados). En primer lugar, explica la presencia en el cine de un escritor héroe y un escritor demonio (2001: 69-118). Mientras que el escritor héroe encarna el triunfo de los ideales americanos y su uso es más restringido — Las aventuras de Marc Twain (The adventures of Marc Twain) (1944) de Irving Rapper es un paradigma-, el escritor demonio ha tenido un recorrido mayor. Este tipo reconocible asume una posición marginal, tiene comportamientos conflictivos, debilidad psicológica y se abandona al alcohol y las drogas. El autor endemoniado es para Bolter el fracaso del yo americano. A diferencia del anterior tipo, este encuentra en el personaje de ficción (sin prototipo real) del cine de los años 40 su mejor desarrollo (p. ej. Un lugar solitario [In a lonely place], Nicholas Ray, 1950). La inversión del modelo se produce en Misery (Rob Reiner, 1990), de la mano de la lectora obsesionada con la obra del protagonista (2001: 104).

Bolter (2001: 119-158) también propone como tipo le savant simplet, denominación que puede traducirse como el sabio ingenuo. Mediante este personaje asocia la creación artística con la afectividad, la maduración emocional, la sexualidad y la reproducción. Lo muestran filmes tales como Los pecados de Teodora (Theodora goes wild, 1936), de Richard Boleslawski o Cena de navidad (Christmas in Connecticut, 1945), dirigida por Peter Godfrey. En ambos casos, la condición de escritoras de las protagonistas está ligada a una actitud ante la vida poco convencional para la época.

En otro apartado titulado L'esthétique populiste, Bolter introduce un tipo que, por concretar, podría acuñarse como el escritor pueblo:

Dans les films analysés ci-dessous, des personnages d'écrivain rencontrent un représentant du «peuple» —une paysanne immigrée, une chanteuse de boîte de nuit, une ouvrière en usine de soutien-gorge, un serial killer (!), un éboueur- avec qui ils nouent une relation allégorique qui renvoie à un débat important du $20 \mathrm{e}$ siècle, le rapport du «peuple» américain à l'art (2001: 164).

En este orden, para Bolter, son filmes representativos Noche nupcial (The Wedding Night), de King Vidor; Bola de fuego (Ball of fire), de Howard Hawks (1941); Como un torrente (Some Came Running), de Vincente Minnelli (1958), o Barton Fink, de Joel Coen (1991).

Hasta el momento se han esbozado dos líneas de investigación con amplio potencial: la dramatización de autores reales en la película biográfica y la identificación de tipos en un contexto genérico más amplio - writer-film, dice Bolter- Sin embargo, la crítica se ha interesado más por una tercera vía que supera el plano del contenido.

${ }^{5}$ La denominación de «autor ficticio dramatizado» — que se ha empleado parcialmente para el escritor real con el objetivo de hacer una distinción (autor real dramatizado) — figura en una contribución de Carlos Javier García. En sus palabras, «mediante el recurso del autor ficticio dramatizado, uno de los tópicos más característicos de la metanovela, el escritor pone ante el lector una novela ya conclusa y, a la vez, en proceso de desarrollo y elaboración. El narrador escribe en presente, como si coincidieran en cada momento la propia historia y su discurso narrativo, y la novela coincide con la novela que se va elaborando [...]» (2005: 70). Sobre el sentido que otorga el investigador a esta figura clave en las estructuras metanarrativas reflexionaremos en adelante. 
Nos referimos a las operaciones discursivas y los artificios narrativos que se generan como consecuencia de la aparición del personaje escritor en la pantalla.

A propósito de Adaptation (El ladrón de Orquídeas) (Spike Jonze, 2002), Laura Marcus asevera que el carácter «radicalmente autorreflexivo» del filme no recae únicamente sobre la historia y el personaje, sino también sobre el propio concepto de adaptación. Este asume una connotación biológica que no se hurta al espectador para sostener el proceso de continua «transmutación» textual (ensayo periodístico-libroguion-película) que tiene lugar en el filme (2013: 41). Otra notable manifestación es la «deconstrucción de un universo teatral» (Abuín, 2012: 80) que se produce en la premiada Shakespeare in love. Además, en esta película, el espectador atestigua cómo la historia de amor de Shakespeare y Viola se cimienta al tiempo de la creación de Romeo y Julieta. Este ejercicio de intertextualidad alcanza su máxima expresión con una confluencia ficcional-metaficcional en el estreno de la obra, cuando ya es imposible distinguir al dramaturgo y a la actriz de los personajes que interpretan. En el mismo orden, Deborah Cartmell observa que «Becoming Jane is an adaptation of Pride and Prejudice insofar as it magnifies parallels between Jane Austen's life and the novel» (2013: 156). Así, la investigadora reconoce la ejecución de una reescritura laxa que sobrepasa ciertos límites ontológicos, pues el hipotexto principal de esta supuesta película biográfica es una novela de la propia autora. Pero el proceso de canibalización no finaliza con Orgullo y prejuicio, máxime si tenemos en cuenta la caracterización de Jane Austen (Anne Hathaway) en el filme: «[Jane] begins the film as Elisabeth Bennet and ends it as Anne Elliot» (2013: 27). Otra película que cuestiona las fronteras de la adaptación cinematográfica con la inclusión de un personaje escritor es Smoke (Wayne Wang, 1995). En palabras de Sánchez Noriega, la película se aleja de las habituales fórmulas que orbitan en torno a la noción de adaptación, «para devenir una forma más rica de diálogo literatura-cine ya que en ella el cuento que le da origen es reproducido con bastante fidelidad en su expresión originaria (oral) y recreado en una nueva (visual); pero también sucede que en la película se plasma el hecho metaliterario de la propia redacción del cuento» (2010: 19). Por otra parte, la dialéctica realidad-ficción se torna aún más compleja en Las horas (The Hours, 2002), adaptación cinematográfica de Stephen Daldry sobre la magnífica novela de Michael Cunningham. En la cinta, la escritura en progreso de Mrs Dalloway no origina un segundo nivel narrativo, sino la emergencia de una hiperficción que abarca tres tiempos y tres espacios que se desarrollan en paralelo. Gracias al montaje, que logra la pretendida simultaneidad de la novela de Cunningham, se procura una relación causal; de tal forma que lo que Woolf (Nicole Kidman) proyecta mentalmente en 1923 determina en 1951 el comportamiento de su lectora, Laura Brown (Julianne Moore). En el tercer tiempo narrativo, correspondiente a 2001, no solo se continúan revisando los aspectos biográficos de Woolf y las constantes argumentales de su obra, sino que una Mrs Dalloway del siglo XXI (Meryl Streep) encarna la actualización del sistema de valores del que Woolf fue visionaria.

Tras lo expuesto puede afirmarse que el personaje escritor se ha consolidado como objeto de estudio a la luz de diferentes perspectivas. Tanto es así que Bolter se plantea si lo que denomina writer-film no debería postularse como género cinematográfico de pleno derecho (2001: 264). Plantea esta cuestión y, a pesar de sus convincentes argumentos, la deja abierta con la firme esperanza de que la investigación que se desarrolle en el futuro le dé finalmente la razón. 
El 26 de marzo del año 2000 Todo sobre mi madre (Pedro Almodóvar, 1999) era galardonada con el premio Óscar en la categoría de mejor película de habla no inglesa. La trama comienza con un joven aprendiz de escritor llamado Esteban (Eloy Azorín), deseoso de relatar la historia de su padre, cuya identidad no conoce. La novela en ciernes se titularía Todo sobre mi padre. Pero la misma noche que su madre se muestra dispuesta a relatarle toda la verdad sobre su progenitor, el joven muere atropellado. Será Manuela (Cecilia Roth) la que tendrá que ir en busca del padre de Esteban para contarle que tenían un hijo en común y así clausurar el relato que el joven nunca finalizó. En esta película, la muerte del hijo es el suceso que articula la transformación de una madre biológica en una madre biográfica en la que caben todas las madres. La fascinación del director manchego por la figura materna supone, en realidad, un bello homenaje a la creación en el sentido de la poiesis platónica. Su apuesta por un filme realizado sobre un andamiaje intertextual e interartístico para abrazar el símbolo de la madre total clausuró el siglo XX con el posicionamiento del cine español en la cúspide del panorama cinematográfico europeo.

La muerte prematura de Esteban en la película más celebrada del cine español de los últimos tiempos se antoja un reclamo para que las relaciones filmoliterarias no aguarden un mismo final. Afortunadamente no ha sido así. A pesar de haberse reducido el número de adaptaciones cinematográficas en la primera década del siglo XXI, la literatura ha continuado formando parte de temática de las películas, también con la representación del profesional literario en las tramas. En aquellos años se estrenaron ochenta y dos largometrajes producidos o coproducidos con capital español en los cuales figuraba un personaje escritor. ${ }^{6}$ Entonces convivían en activo cuatro generaciones de cineastas cuyos máximos exponentes dejaron que el hecho literario influyera, en mayor o menor medida, en el argumento y en el andamiaje narrativo de sus películas documentales o de ficción. Los ejemplos son numerosos: desde Carlos Saura o José Luis Garci a Isaki Lacuesta o Cesc Gay; sin olvidar a David Trueba que adaptó Soldados de Salamina (2003), autoficción de Javier Cercas (2001). Diez años después de que recogiera el galardón de la Academia de Hollywood, Pedro Almodóvar se lo entregaba a Juan José Campanella, que lo recibía por la misma categoría. También por ceder la palabra a un personaje que pretendía reescribir una historia de su pasado en la coproducción hispano-argentina El secreto de sus ojos (2009), la reescritura cinematográfica de una novela de Eduardo Sacheri (La pregunta de sus ojos, 2005).

Pero fueron muchos más los escritores que ocuparon la pantalla en esta década. Por ejemplo en películas biográficas como Al sur de Granada (Fernando Colomo, 2003), Teresa: el cuerpo de Cristo (Ray Loriga, 2006), El cónsul de Sodoma (Sigfrid Monleón, 2009) o Lope (Andrucha Waddington, 2010). Mención especial merecen también dos documentales, Lorca, el mar deja de moverse (Emilio Ruíz Barrachina, 2006) y Cravan vs. Cravan (Isaki Lacuesta, 2002). El último seguía la pista del poeta y boxeador Arthur Cravan, desaparecido en el Golfo de México en 1918. Un caso especial es Soldados de Salamina, cuya trama gira en torno a un episodio vivido por Rafael Sánchez Mazas. Javier Cercas firma la novela en la que está inspirada el filme y cede su

6 Datos obtenidos en los Anuarios del Cine Español (2001-2010). Estas publicaciones del Instituto de la Cinematografía y de las Artes Audiovisuales (ICAA) recogen la información sobre las películas cinematográficas producidas con capital español. También disponible en: $<$ http://www.culturaydeporte.gob.es/cultura/areas/cine/mc/anuario-cine/portada.html $>$. 
identidad en la película a Lola Cercas (Ariadna Gil). Trueba reconoció el desafío de adaptar esta propuesta autoficcional - máxime sin la presencia de Javier Cercas en pantalla - pero lo aceptó: "suponía un nuevo viaje a una nueva primera persona, a un nuevo yo para contar la historia» (2003: 92).

Los escritores sin referente real también proliferaron en este tiempo. Uno de sus hilos conductores, como ya se indicó de la mano de Bolter, es el paralelismo entre educación sentimental y escritura creativa. En este marco destaca El camino de los ingleses (Antonio Banderas, 2006), adaptación de la novela homónima de Antonio Soler, quien también firma el guion. Las aspiraciones literarias del joven Miguelito Dávila, protagonista de la película de Banderas, contrastan con el retrato del consagrado autor Blas Otamendi en Historia de un beso (2002). José Luis Garci presenta a un escritor ficticio que ha alcanzado el éxito en su faceta profesional pero que no puede desprenderse de una historia de amor del pasado que lo detuvo en el tiempo. La memoria también redime al famoso escritor de Roma (Adolfo Aristarain, 2004), interpretado por José Sacristán, para quien el recuerdo de su madre es razón suficiente para continuar escribiendo.

La necesidad de recuperar un tiempo pretérito a través del acto de escritura es una constante temática en estos filmes, lo que se traduce en el establecimiento de una estructura narrativa en la que la metaficción se articula asimismo como un flashback de la vivencia de los protagonistas. Así sucede en Roma, pero igualmente en El secreto de sus ojos. De otro modo, con el recurso de la metaficción se explican los sentimientos de la protagonista de La puta y la ballena (Bigas Luna, 2004), una enferma de cáncer para quien la escritura es terapéutica.

La búsqueda de inspiración es otra clave temática en este tipo filmes y en esta década orbita en torno a la figura del personaje guionista. Es el caso Ficción (Cesc Gay, 2006), una hermosa película sobre emociones contenidas que, además, recrea otro tópico ya explorado en este trabajo: la oportunidad de convertir en ficción lo que su realidad no les permite vivir. Otro ejemplo es La mala educación (2004), de Pedro Almodóvar. El manchego confiesa en el prólogo del guion de esta película que la literatura le sirvió como punto de encuentro de los personajes. Así, en la película hay dos escritores, pero también un antiguo profesor de literatura transformado en editor. En esta década, Almodóvar nos regalaría también a Marco Zuluaga, autor de guías de viaje en Hable con ella (2002) y, por último, a Harry Caine (Mateo Blanco), el guionista y cineasta ciego de Los abrazos rotos (2009).

Son muchos los guionistas y directores que han contribuido a dignificar esta figura en nuestras ficciones, pero fue el director donostiarra Julio Medem quien abrió un nuevo ciclo en el primer año del siglo XXI con la primera película española rodada en video digital de alta definición. Su sugerente título, Lucía y el sexo, y también su alto contenido erótico atrajeron al público a las salas, lo que se tradujo en más de cinco millones de euros de recaudación. Medem se desprende de la libreta del joven escritor de Todo sobre mi madre y sitúa al espectador frente a una pantalla de ordenador, presente ya en los títulos de crédito, que inaugura un espacio virtualmente alternativo - como si de una isla se tratara - al que todos los personajes se dirigen en busca de una historia que se reescribe continuamente.

Pero esto no solo sucede en la ficción, sino también fuera de ella. En la memoria del filme, paratexto previo al guion publicado tres meses después del estreno, Medem habla de la escritura de dos versiones previas a la definitiva. Después reconoce que fueron seis $\mathrm{y}$, años más tarde, confiesa que fueron diecinueve en una entrevista 
concedida a El Cultural. ${ }^{7}$ Con todo, puede comprobarse que existen algunos cambios sustanciales si comparamos el guion con lo que se proyectaría finalmente. El primer cambio, del que hablaremos más detenidamente en adelante, se produce ya en la secuencia 0 , correspondiente a los títulos de crédito. Tal y como se produce la mostración de los mismos, parece que se estuvieran escribiendo en tiempo presente desde un hipotético teclado que podría ser el de un personaje. O el de Medem. No importa. En cualquier caso, se entiende que la historia demanda un receptor para construirse in progress al otro lado de la pantalla.

ESCRITORES ANTE LA PANTALLA: LUCÍA Y EL SEXO (JULIO MEDEM, 2001)

«Lucía, un rayo de sol»: la primera versión del guion de Julio Medem (o la primera novela de Lorenzo en la ficción)

Bolter afirma de la mano de David Bordwell que la tarea cognitiva que subyace en el proceso de comprensión del relato es un desafío placentero para el espectador (2001: 204). Apoyándose en la teoría psicocognitiva del estadounidense, a su juicio, el esfuerzo del espectador se intensifica particularmente cuando se trata de desgranar filmes protagonizados por personajes escritores. De alguna manera, esta figura encarna un proceso de creación expuesto ante los ojos del espectador, cuya actividad también se tematiza generalmente en estas películas. Para Bolter, esto se traduce en la implicación consciente del espectador en la construcción del filme gracias a la identificación espectador-personaje que permite que el primero asuma la posición de reescritor:

[...] le film sur l'écrivain valorise l'équivalence du spectateur et du personnage. Il potentialise l'identification en faisant converger le processus de la réception avec celui de la création, dont il est question à l'intérieur du film, mais aussi avec les instances créatives dont le film est issu. Le personnage-écrivain se réfère, en les reflétant, au scénariste, à l'acteur, au cinéaste — mais aussi au récepteur. L'écriture peut métaphoriser toutes les autres formes de création artistique: ainsi, le scénariste, le cinéaste, l'acteur ont chacun à leur manière «écrit» sur la table rase de la pellicule. L'écrivain diégétique écrit: le spectateur «réécrit» en déchiffrant la diégèse. Le lien conceptuel se révèle dans des ressemblances physiques. L'écrivain travaille le plus souvent en position assise, faisant écho à l'attitude du spectateur. Cette similarité posturale est d'ailleurs valorisée au plus haut point par l'image classique de l'écrivain à sa feuille, dans laquelle le point de vue du spectateur est aligné sur le sien. Ce qu'écrit ce personnage - le «texte-dans-le-texte»- est une spécificité du «filmécrivain». Quant à la page blanche de l'écrivain diégétique, elle est une métonymie du grand rectangle blanc de l'écran, sur lequel cinéaste et récepteur «écrivent» en même temps leurs versions complémentaires de la diégèse (2001:262).

La apuesta de Bolter es muy sugerente. Existe una primera identificación personaje-espectador favorecida por una posición equivalente: ambos están sentados frente a una pantalla y ambos comparten la tarea de (re)escribir un relato. Pero si este personaje refleja al espectador, también hace lo propio con los autores de la película, pues guionista y director están implicados implícitamente en el proceso creativo de la

${ }^{7}$ Disponible en: $<\underline{\text { http: } / / \text { www.elcultural.com/revista/cine/Con-Lucia-y-el-sexo-me-lo-he-puesto- }}$ $\underline{\text { muy-dificil/159>. }}$ 
historia. ${ }^{8}$ Por lo tanto, tal y como sugiere Bolter, el grand rectangle blanc de l'écran cataliza tres escrituras complementarias: la metadiegética del personaje, la diegética, de un meganarrador articulado por director y guionista, y, por último, aquella virtual que el espectador materializa en el proceso de recepción del relato.

En suma, la dinámica relacional (que según Bolter incluye a todo el equipo técnico y creativo del filme) que orbita en torno al personaje escritor activa inmediatamente el reto cognitivo de la recepción y la puesta en funcionamiento de su «encyclopédie mentale». En conclusión: «Quand on envisage la narration et la réception d'un film comme le processus coopératif continu que décrit Bordwell, conduisant du créateur au récepteur, les opportunités que porte en lui le «film-écrivain» apparaissent clairement» (2001: 210). Después de todo, como el escritor dentro de la pantalla, el espectador fuera de ella tiene ante sus ojos una historia que está por escribir.

A continuación, exploraremos este aparato reflexivo que implica a los sujetos equivalentes autor-personaje-espectador en la construcción de Lucía y el sexo. La elección de esta película es debida a la lectura de un paratexto revelador que precede al guion del filme y que nos permite conocer el posicionamiento de Medem en este juego de espejos. ${ }^{9}$ Sus confesiones no solo nos permiten justificar la teoría de Bolter, sino alumbrar cómo el proceso de recepción se enriquece con la experiencia del cineasta que, como el personaje escritor de su película, reescribe su historia una y otra vez. De hecho, el abrazo de Lorenzo (el escritor) y Lucía (la lectora) al final del metraje es una bella metáfora de la actividad conjunta que creador y espectador han llevado a cabo. Pero empecemos por el principio.

Lucía y el sexo es la inmediata y necesaria respuesta a su anterior película, Los amantes del círculo polar (1998). En dicha historia, el azar teje durante años la relación amorosa de Ana y Otto que, por otra cruel casualidad, finaliza con la muerte del protagonista masculino. Por ello, en su nuevo trabajo «la carrera inicial de Lucía partiría de la carrera final de Ana, sólo que con el signo vital cambiado, es decir, de la muerte a la vida» (2001: 7). Cuenta el director en su reveladora memoria que tras el inesperado éxito de Los amantes del círculo polar se marchó a Formentera llevando consigo una pequeña cámara de video digital:

Lo primero que grabé con la cámara fue mi propia sombra reflejada sobre la estela del barco que me llevaba a una pequeña isla del Mediterráneo. Tuve la sensación de estar dejándome atrás, poniendo ese mar de por medio entre lo que había sido y hecho hasta entonces, donde había dejado mis cosas, y algo nuevo que no conocía. La imagen de la espuma del mar batiendo mi sombra me podía servir para lavar también a Lucía, que

${ }^{8}$ Una idea similar es defendida por Mary Catanzaro (2004) en el marco literario. La autora reflexiona en uno de sus trabajos sobre el escritor ficticio como voice of self-invention. A su juicio, este personaje - que ella estudia a partir de la obra de Samuel Beckett Malone meurt (1951) — vehicula una especial relación entre el autor real (Beckett) y el autor ficticio no profesional (Malone): «Indeed, both Beckett and Malone find storytelling and writing significant on many levels, from the intimately personal to the public. The writer not only always has the chance to speak to his character and to us, the readers, but writing allows him also to return home in his works») (2004: 132). A juicio de Catanzaro, Beckett se sirve de su personaje para inaugurar un juego especular que le permite visitar sus propias obras que, como la vida, también pueden reescribirse. Así, Malone también le permite explorar el poder sanador de la escritura como alternativa a la realidad.

${ }^{9}$ La memoria de Lucía y el sexo también está disponible en la página web de Julio Medem: $<$ http://www.juliomedem.org/filmografia/archivos/lucia memoria.pdf $>$. 
necesitaba ser nueva. Borrarse la persona. Éramos dos sombras en una ¿Qué tiene de malo? (2001: 7).

Así comienza un proceso de «descubrimiento» que define como «materia fundamental» de la película (2001: 8), y no nos hurta, como veremos a continuación, que se opera en varios planos.

Tras los títulos de crédito, la imagen funde a negro y sobre la pantalla se escribe el nombre de Lucía. Creyendo que ha muerto su novio Lorenzo (Tristán Ulloa), la joven Lucía (Paz Vega) hace las maletas, toma un barco y se dirige a la isla de la que tantas veces le había hablado su pareja para bañarse de sol: «Sola. Sola me insolo - tajante¡No me voy a bañar!... ¡Me voy a insolar!» (2001: 26). Cuenta Medem que, como Lucía, comenzó recorriendo la isla en moto. Los dos descubren en un extremo de esta un agujero y un faro, símbolos por excelencia de la historia. Tras esta revelación - que adquirió una connotación sexual- explica: «me estaba inundando de luz, tontamente, cuando decidí que lo más importante es que esa historia fuera terapéutica», ubicada en una madre isla que acogiera a los que quieren huir de la tragedia $\mathrm{y}$, también, una cuestión sumamente relevante, «no quería sexo para Lucía» (2001: 8).

Bajo esas premisas escribió la primera versión del guion, titulada Lucía, un rayo de sol, sin que hubiera aparecido el personaje de Lorenzo, el escritor ficticio que traería consigo el sexo. Esa fábula que nunca rodó trataba el encuentro casual de unos personajes (Lucía, Carlos y Elena) que se han marchado a la isla fugándose de una tragedia. Pero solo cuando inventó a Lorenzo, meses más tarde, cayó en la cuenta de que «hay huidas que no van del todo hacia delante porque antes de llegar muy lejos pueden volver atrás para enfrentarse y resolver algo pendiente, justo en el punto de origen de la fuga» (2001: 8).

Quizá, por ello, en la versión que se proyectaría en los cines, cuando Lucía cae por el agujero que acaba de descubrir, no llega a alcanzar el mar, sino que la imagen funde a negro y, sobre ella, se lee el sexo: seis años antes. ${ }^{10}$ Un flashback nos conduce al mar de la isla en el que aparece por primera vez Lorenzo haciendo el amor con una desconocida que dice ser valenciana y cocinera. Él solo le confiesa que es de Madrid y que esa noche es la de su cumpleaños. Aunque el espectador lo desconozca, ellos son Lorenzo y Elena (Najwa Nimri).

Curiosamente, en la versión definitiva de Lucía y el sexo, también Lorenzo escribirá varias novelas. El mismo día que su agente literario le propone que incluya aquella anécdota sexual veraniega para su futuro relato, el escritor conoce a Lucía. Ella, una camarera de un céntrico restaurante madrileño, le había perseguido en silencio varios meses hasta que se decide a declararle sus sentimientos: «He leído tu novela, varias veces, y... ya no he podido leer nada más» — le dice—, «se me ha agarrado por

${ }^{10}$ El capítulo de la película denominado «Lucía» refleja la llegada del personaje femenino a la isla y sus primeras reacciones. Por un lado, la protagonista reconstruye en la ficción el viaje que hizo el director cuando estaba ideando la película. Pero, además, de forma consciente, ella actúa como uno de los personajes de la novela de Lorenzo, que Lucía ha leído previamente, pero cuyo contenido es desconocido por el espectador en ese momento del metraje. Además, en el capítulo cinematográfico, a diferencia del guion, no se produce el encuentro de Lucía con Carlos y Elena, los que quedarán definitivamente instalados en el sexo. Si en el guion Lucía conoce a Carlos en la secuencia 18B, en la película editada se altera el orden. La secuencia 18B se corresponde con la secuencia 41, situada inmediatamente después de otra en la que Lorenzo está escribiendo su novela y su voz, en off, revela parte de su contenido. Habla de una joven que dice ser de Malta y que conocerá a un auténtico Maltés. En la siguiente secuencia se produce el primer encuentro entre Carlos y Lucía. 
dentro, y no me suelta» (2001: 43). A partir de entonces comienzan una vida en común $\mathrm{y}$, en medio de esa época gozosa, Lorenzo escribe esa primera versión de su futura novela mezclando datos de la vida de dos mujeres, Lucía y Elena: «El restaurante se hizo famoso en Madrid gracias a las paellas de aquella joven solitaria y sin habla que aún seguía recordando a su abuela enterrada en el pueblo junto a sus padres. Cuando algún cliente se interesaba por ella, para justificar su timidez, respondía que era de Malta». ${ }^{11}$

Cuando acaba la novela, él aguarda tan nervioso la reacción de su pareja que incluso ella llega a decirle que parece que esté esperando un parto: «Exacto - contesta el autor - Y tú eres la madre» (2001: 64). Después de leerla, Lucía reconoce que no le ha gustado, quizá, argumenta ella misma, porque no la ha leído mientras él la escribía. Pero Lorenzo, quien había continuado dicha historia con su imaginación, no era consciente de que se estaba construyendo en sí misma: su agente literario le comunica que su hermana asistió en un parto a una madre soltera que alumbró una niña llamada Luna. Esta se marchó a Madrid después de haber conocido al padre de su hija en una isla del Mediterráneo la noche del cumpleaños de él.

Esta nueva casualidad determina que el escritor desestime continuar trabajando en este texto en el que la protagonista sí tomó la decisión de abortar. En el guion, la secuencia en la que el agente literario le comunica el secreto (secuencia 45) figura anteriormente a la reacción de Lucía (secuencia 46). Pero este desorden ratifica que lo que lleva a Lorenzo a rechazar la primera versión de su novela no es el hecho de conocer el verdadero cauce que tomó la historia, sino la respuesta de Lucía, la madre lectora. Lorenzo, como Medem con su primer guion, vuelve a recomenzar.

«El sexo, antes del sol»: la segunda versión del guion de Julio Medem (o la segunda novela de Lorenzo en la ficción)

La segunda versión del guion que elaboró Medem recibió el título de El sexo, antes del sol. Esta vez se centró en escribir el pasado de los distintos personajes teniendo en cuenta un hilo conector: el sexo. Pero según cuenta en la memoria del filme, el hecho de jugar con vidas ajenas hizo que se sumergiera en una crisis creativa que solucionó a través de un personaje. Hasta entonces Lorenzo era músico, pero tenía que ser escritor:

La solución llegó en el momento más desesperado, cuando decidí, con rabia, proyectar toda mi confusión creativa en un solo personaje del pasado: Lorenzo. Fue así, convirtiéndolo en escritor y rebajando sustancialmente el espesor, también el número, del resto de los personajes, como me hice pasajero y comencé a mirar la historia a través de las ventanillas de su vagón (2001: 10).

${ }^{11}$ Esta frase escrita por Lorenzo y pronunciada en off (37:00) no aparece reflejada en el guion pero refleja perfectamente la mezcla a la que nos referíamos. Elena, la mujer de la isla, había dicho a Lorenzo que cocinaba paellas en un restaurante de Valencia y, por otra parte, Lucía, en una de sus primeras conversaciones con el escritor, cuenta a Lorenzo que se crió con su abuela tras la muerte de sus padres. Esta charla entre los protagonistas es muy reveladora para la caracterización del personaje femenino como lectora: «Me dijo que mis padres y mi hermana mayor se habían ido a abrir una papelería al cielo, justo enfrente de una escuela de ángeles. Papelería librería ¿eh?...es que la que tenían en el pueblo no daba mucho dinero. [...] Me lo contó tan bien todo...que aún me lo creo. Siempre me ha gustado la gente que sabe contar la vida a su manera ¡Me dan confianza!» (2001: 48). 
Este significativo párrafo materializa la teoría de Bolter pues, como dijimos, el personaje escritor refleja al autor real en el espacio virtual que ambos comparten. Cuando Medem convirtió a Lorenzo en escritor los dos guiones previos se fusionaron en Lucía y el sexo. Pero si Medem necesitaba a Lorenzo, un escritor que edificara la historia desde el corazón de la diégesis, también necesitaba a Lucía, la lectora que la sostuviera.

El director dejó clara esta premisa en la secuencia 0 que figura en el guion, en la cual, a priori, aparecerían los títulos de crédito en sobreimpresión. Como ya anticipamos, esta primera secuencia se eliminaría más tarde pero su contenido merece que nos detengamos en su análisis. En ella se alternan dos escenarios. En el primero, una playa, figuran un hombre (Lorenzo) y una niña (Luna, hija de Lorenzo y Elena) manteniendo una conversación. Y en el segundo de ellos aparece una mujer (Lucía) leyendo en la pantalla de un ordenador lo que se acaba de mostrar a los espectadores en imágenes. Su presencia coincide con una voz en off, la del hombre de la playa, que continua enunciando el relato: «¿Cuánta importancia tenía ser padre si su hija no lo sabía?» (2001: 15). Durante esta secuencia, el espectador identifica a la mujer como la lectora, mientras que el hombre es el personaje y, a su vez, la instancia enunciadora de un relato metadiegético. Con el avance del metraje descubriríamos que la imagen de ese hombre se corresponde con la de Lorenzo, el novio de Lucía, quien ha escrito la historia que ella estaba leyendo, el segundo intento de novela que escribe en la película inspirado en su propia vivencia.

Pero en esta secuencia es Lucía quien ha proyectado la imagen de su pareja en el personaje de la metaficción, ya que el espectador no ha visualizado el acto de escritura, sino el de lectura. Con esta suerte de obertura, Medem pretendía proporcionarnos las herramientas necesarias para el espectador, el último en incorporarse a la escritura de esta historia. Lucía y el sexo, cuyo discurso alterna continuamente dos tiempos - el presente y el pasado de los protagonistas - incluye un segundo nivel narrativo que atesora un segundo relato. Este es, en primera instancia, la proyección de las diferentes novelas que va escribiendo Lorenzo. Sin embargo, la actualización del mismo a los ojos de otros personajes, lo convierten en un metarrelato múltiple (a merced de todas las posibles proyecciones del mismo).

La eliminación de esta secuencia determina que los títulos de crédito aparezcan al ritmo de un tecleo y se muestren en lo que se antoja una pantalla de ordenador. Una interfaz que, según avanza el metraje, captura la mirada de Lorenzo (el escritor), también la de Lucía (la lectora), pero, sobre todo, la del espectador. En palabras de Pascale Thibaudeau, «por la interfaz de la pantalla del ordenador se abren las compuertas que hacen comunicar los distintos niveles narrativos y permiten su mutua contaminación» (2011: 27). Esta reconfiguración de la primera secuencia evidencia la puesta en escena de una escritura in progress que se afirmará a lo largo del filme y de la que el espectador es el principal destinatario involucrado.

Sin embargo, la secuencia 0 no desaparece en su totalidad, sino que se reescribe en la secuencia 49. En el guion, esta secuencia figura como «repetición parcial de la secuencia $0 »$, pero el montaje final presenta una mezcla entre ambas como explicaremos a continuación. Tiene lugar después de que Lorenzo, sin revelar su identidad, conozca a su hija Luna (Silvia Llanos) en un parque (secuencia 48). El escritor quedará fascinado con la vivencia de Belén (Elena Anaya), la niñera de la niña, una adolescente que no oculta su atracción sexual por Antonio (Carlos [Daniel Freire]), el amante de su madre. 
El encuentro con Luna y el relato de Belén serán los principales detonantes de la reanudación de la escritura, tal y como se refleja en la secuencia posterior.

En ella figuran dos escenarios, la playa y el despacho, pero esta vez se alterna el acto de escritura (Lorenzo frente al ordenador) con el acto de lectura (Lucía frente al ordenador). Con este cambio se subraya la puesta en escena de un metarrelato producto de la intersubjetividad de ambos y, a través de él, la materialización de un nuevo desafío: si hasta el momento el espectador ha tratado de comprender el proceso creativo del personaje-escritor (Lorenzo) con el que se ha identificado, ahora ha de hacerlo también con el personaje-lector (Lucía), a quien se otorga el derecho de vivificar mentalmente la historia de Lorenzo. Así, la dinámica relacional autor-personajeespectador propuesta por Bolter se complica con la intervención de Lucía.

En Lucía y el sexo, como ya anticipamos, la pantalla del ordenador simboliza la entrada a dicho universo virtual en el que se produce un proceso de sugestión. De hecho, Medem asegura en la citada memoria que una vez que desahogó su responsabilidad como escritor en Lorenzo y su responsabilidad como lector en Lucía, la película hubiera podido llamarse La sugestionada y el sugestionador (2001: 10). Sin embargo, como veremos a continuación, la sugestión alcanza a todos los personajes de la película.

La novela de Lorenzo avanza gracias a las conversaciones que mantiene con Belén. ${ }^{12}$ En la secuencia 57 Belén confiesa a Lorenzo en el parque que se masturbó visionando una película porno de su madre (nivel diegético) y seguidamente, en la secuencia 58, se reproduce audiovisualmente el contenido de dicha confesión (nivel metadiegético desplegado por Lorenzo). Aparentemente, esta transición despliega una mise en abyme de la enunciación de carácter productiva que, siguiendo a Lucien Dällenbach, supone la transformación de la existencia a través de la escritura (1991: 100). Lorenzo no solo se apropia de la historia de Belén, sino que origina una metalepsis cuando él mismo transgrede el nivel narrativo para proyectarse en dicho amante, que aparece cuando la joven se está masturbando para iniciar relación sexual con ella (Belén solo lo sugiere). El escritor, sujeto de la enunciación narrativa, se convierte en objeto de la misma habiendo sido vampirizado por las palabras de Belén.

La secuencia 59 nos muestra de nuevo a Lucía leyendo en su casa mientras la voz en off de Lorenzo continúa enunciando el relato: «Casi se matan de placer. Él tuvo que taparle la boca para que no despertara a su madre» (2001: 76). A continuación, la secuencia 60 nos muestra a Lucía en el salón de Belén haciendo el amor con Lorenzo.

12 Thibaudeau sostiene que son tres las historias que Lorenzo escribe en Lucía y el sexo. La primera se distingue claramente tal y como se explicó en el epígrafe anterior. Pero los límites entre la segunda y la tercera ficción son difusos. La segunda corresponde al encuentro del hombre y la niña en la playa, historia que Lorenzo no sabe si continuar porque «no tiene ni idea de lo que es ser padre» («Invéntatelo», responde Lucía ante las dudas de su pareja). Para Thibaudeau (2011: 27), la tercera se inauguraría con la ficcionalización del personaje de Belén (y su relato). Pero, a nuestro juicio, esta puede ser considerada como una continuación de la segunda, ya que la escritura de la misma se encuentra en el «capítulo III», tal y como lo muestra la pantalla del ordenador de Lorenzo. En cualquier caso, los límites en la estructura narrativa (relato diegético y relatos metadiegéticos, así como entre los distintos relatos metadiegéticos) son difusos. De hecho, Thibaudeau sugiere que «el espectador nunca podrá decir si el encuentro de Lorenzo con Luna ha tenido lugar en la realidad diegética o solamente en la ficción metadiegética». Es más, «la realidad del personaje de Belén es así sometida a cuestionamiento, aparece más como un avatar fastasmático de Lucía, una proyección literaria, que como un personaje real, pero esta hipótesis tampoco se puede garantizar. No es que Belén sea a la vez personaje real y personaje de ficción sino que es a a la vez personaje real y de ficción más sólo personaje de ficción» (2011: 25-28). 
Lucía se proyecta en Belén y asimismo proyecta a Lorenzo en el amante de esta. De acuerdo con esto, sugestionada por sus palabras y visiblemente excitada, en la secuencia 61, deja de leer para acudir a la habitación donde Lorenzo duerme. En definitiva, si lo contado por Belén sirvió para elaborar una ficción, ahora, el relato metadiegético tiene una fuerza performativa en el marco diegético.

La materialización del relato finaliza en la secuencia 62, con Belén y Lorenzo abrazados tras culminar el acto sexual, mientras la voz en off de Belén concluye: «Hemos decidido no contárselo a mi madre. Y no volver a hacerlo, nunca más» (2001: 76). Sin embargo, la secuencia 63 - en realidad, la continuación de la secuencia 57 como se explicita en el guion- es reveladora. Belén concluye su conversación con Lorenzo en el parque sin dejar claro lo que ocurrió aquella noche: «Empecé a masturbarme para ti, y acabé pensando en él, pero no lo hicimos. [...] O eso creo» (2001: 77). El espectador, entonces, reordena mentalmente las secuencias deduciendo que, a partir de esa ambigüedad, se cimienta la escritura de Lorenzo que, a su vez, propicia la excitación de Lucía, que provoca un efecto real en la diégesis.

Las proyecciones, mejor aún, las incursiones del escritor ficticio y la lectora ficticia en un segundo nivel narrativo determinan la construcción conjunta del metarrelato, máxime cuando se enfatizan los procesos de enunciación y recepción. Dichas proyecciones se operan en un espacio virtual - la pantalla de ordenador simboliza la entrada al mismo - que permite que los límites entre realidad y ficción se diluyan. Apunta Gérard Genette que «la historia metadiegética puede tener (...) el mismo estatuto de "realidad" que la diégesis en la que se la relata» (2006: 24). Pero esta idea ha de ser valorada en última instancia por el espectador. Este, sentado también frente una pantalla, entra en el espacio virtual para llevar a cabo esa tarea de «reconocimiento» que anticipan los personajes en el nivel diegético. Solo que, en su caso, el esfuerzo es mayor: se precisa que actualice el relato en su conjunto con toda la información que Medem le proporciona.

\section{LUCÍA Y EL SEXO: UN CUENTO LLENO DE VENTAJAS}

Ya esbozamos al inicio que desde que Medem descubriera el agujero en el extremo de la isla, este se convertiría en el símbolo más recurrente en el filme. Su verdadero significado viene de nuevo por boca de Lorenzo el día que el escritor y Belén aprovechan una salida nocturna de Elena, la madre de Luna, para dar rienda suelta a sus deseos. Antes de que Luna concilie el sueño, este le relata un cuento sobre «la isla en la que nadie se muere...en la que si te caes por un agujero, puedes elegir la vida que quieras» (2001: 83). Cuando se duerme, justo después de que los amantes comiencen a acariciarse, la niña será devorada por el perro de la familia. Pero Medem, en lugar de mostrarnos la horrible escena, nos hace caer por un agujero hasta encontrarnos con Luna que, en el fondo del mar, se abraza a su madre convertida en una sirena. La cámara nos devuelve a la superficie en la que puede verse la parte sumergida de un barco que lleva a Elena. Ella es la primera que huye a la isla donde concibió a su hija para fugarse de la tragedia acontecida en Madrid.

Mientras tanto, en la capital, Lorenzo sufre lo que Jesús Angulo y José Luis Rebordinos han denominado «profunda escisión» entre dos aspectos, «la felicidad de su vida con Lucía, conscientemente mostrada de una manera más o menos convencional argumentalmente, y un mundo interior habitado por angustias» que su pareja no puede 
comprender (2005: 82). Lorenzo no ha vuelto a saber nada de Belén desde que huyó de la casa tras el trágico suceso. Sin embargo, sabe que se encuentra bien gracias a Pepe, el agente literario, que una vez más le insta para que vuelva escribir, esta vez en un canal de chat, en el que puede encontrar a Elena bajo el seudónimo de «alsi» (isla escrito al revés).

Reanuda entonces la escritura de dos formas. Por un lado, comunicándose con Elena a través del chat —ocultando su identidad bajo el seudónimo de «farero»— con el objetivo de contarle un cuento terapéutico que ella recibe con agrado: «La primera ventaja es que cuando el cuento llega al final, no se acaba, sino que se cae por un agujero y...iguujjhuu!...y el cuento reaparece en mitad del cuento. Esta es la segunda ventaja, y la más grande, que desde aquí se le puede cambiar el rumbo, si tú me dejas ¡Si me das tiempo!» (2001: 102). De acuerdo con Thibaudeau, «el cuento lleno de ventajas que le propone Lorenzo a Elena es, por supuesto, una definición autorreflexiva del relato de la película que no deja de volver sobre sí mismo para explorar nuevas pistas y evitar, precisamente, que mueran los personajes» (2011: 30). Por otro lado, Lorenzo reanuda la novela. En ella, los tres personajes (Belén, su madre y la pareja de su madre [Antonio/Carlos]) enferman de sexo, hasta que una noche decide acabar con las protagonistas de su relato (secuencia 117): «Las voy a matar de una puta vez. A las dos. Ahora mismo» (2001: 107).

Inmediatamente después en el metraje, Lucía — para quien es imposible comprender el estado depresivo de su novio- reprende duramente a Lorenzo. Esta escena posiciona al espectador en el tiempo diegético anterior a la secuencia inicial de la película. Y un fundido a negro clausura definitivamente el tiempo pretérito para mostrar a Lorenzo en una cama de hospital.

Lucía es la tercera en llegar a Formentera, pero es a la primera a la que vemos llegar en el inicio del filme convencida de la muerte de Lorenzo. Se reafirma en su hipótesis, leyendo una vez más, esta vez una nota que le había dejado el escritor: «perdóname. Es lo último que te pido» (2001: 20). Lo que no sabe Lucía es, que, durante su estancia en la isla, Lorenzo se está recuperando en la UVI tras haber sido atropellado por un coche. Elena, Carlos y Lucía están viviendo en la isla sin saber nada el uno del otro, salvo que todos tienen motivos por los que huir. Así, Elena desconoce que Lucía es la pareja del padre de su hija. Del mismo modo, Lucía ignora la existencia de Elena en la vida de Lorenzo y la paternidad de este. Por último, Carlos — solo el espectador sabe que Antonio es su verdadero nombre - es el amante de la niñera de la hija de Elena, aunque esta no lo sepa.

Finalmente, Lucía y Elena, una vez más frente a una pantalla del ordenador, descubren que Carlos está en paradero desconocido junto a otras dos mujeres: Belén y su madre. Elena rápidamente vincula a Carlos con Belén, pero Lucía comienza a reconstruir la historia a partir de la ficción de su novio. Las siguientes escenas están gobernadas por la voz en off de Lorenzo, que finaliza su novela con la muerte de Belén y su madre bajo la atenta mirada de él mismo y, después, de la de Carlos tal y como sucediera en las secuencias que explicamos en anteriores páginas. La voz en off se escucha también mientras Lucía lee en Madrid lo relatado por Lorenzo y mientras lo recuerda, meses después en la isla, mientras ella mira la pantalla con la fotografía de Carlos desaparecido. Sobre el rostro de Lucía, haciendo memoria de lo leído en el pasado, pronuncia Lorenzo la última frase de su novela: «iY eligió escaparse, borrarse, ser nuevo, cambiarse la sangre entera!» (Medem, 2001: 110). 
Medem deja la incógnita irresuelta. Cada espectador de esta historia, como hace Lucía en el plano diegético — confiando en su inocencia-, tendrá que reescribir la verdadera historia de Antonio (Carlos). Lo último que sabemos es que cae por el agujero de la isla, aquel que permite huir hacia atrás y empezar de nuevo, es decir, rectificar. Por ello depende de los deseos del lector, «convertido ahora en lectautor» - asevera Abuín a propósito de este cuento lleno de ventajas que es Lucía y el sexo-, ir «en busca de un final feliz quizás merecido para sus sufridores protagonistas» (2006: 130). Un último apunte: la desaparición del «yo sexual» - no en vano el nombre de Carlos contiene la palabra sol, en clara referencia a Lorenzo - trae consigo la restauración del «yo creador». Lorenzo, acompañado por el agente literario que siempre le sugirió cómo continuar su historia, llega a la isla para pedir perdón a Elena, pero, sobre todo, para reencontrarse con Lucía. Solo gracias a ella - concluye Medem en su memoria— «Lucía y el sexo es una historia de amor» (2001: 11).

\section{CONCLUSIÓN}

A lo largo de este artículo se ha podido comprobar que la presencia del personaje escritor en pantalla enriquece las tramas fílmicas, suscita una tipología propia, cuestiona los límites de los géneros y genera un potente aparato discursivo que permite experimentar con diversas técnicas narrativas. Lucía y el sexo es un ejemplo paradigmático de lo anteriormente mencionado, pero también permite comprobar cómo la puesta en escena de un personaje escritor puede ser un detonante fundamental para que el espectador se sienta partícipe del proceso de reescritura implicado en la recepción fílmica. En el caso examinado, esto se manifiesta mediante la puesta en marcha de un relato metadiegético íntimamente relacionado con el relato marco que lo contiene.

Lorenzo lleva a cabo la escritura de dos novelas, ambas inspiradas en sucesos acontecidos en su propia vida y ambas inconclusas. El segundo metarrelato se produce in progress en el filme y su creación se alterna con la lectura que efectúa Lucía del mismo. Esto vehicula que escritor y lectora se proyecten como personajes de la ficción que tienen ante la pantalla, focalización que se complica en las secuencias dominadas por el relato de Belén. Así, la construcción múltiple de la novela de Lorenzo se transforma en una operación intersubjetiva que representa metafóricamente la actividad de los espectadores en el proceso de recepción.

No obstante, Trudy Bolter sostiene que el fenómeno identificativo no se agota con la relación personaje escritor-espectador, sino que esta figura también refleja la propia actividad del equipo creativo del filme. Así se cumple en la película analizada, máxime cuando Medem reconoce en la memoria de la misma que, convirtiendo a Lorenzo en escritor, «me hice pasajero y comencé a mirar la historia a través de las ventanillas de su vagón. Lorenzo es ya, gozosamente, la mano que mueve el destino de todos los personajes, y su relación con Lucía da un sentido largo y aglutinador a la historia. Su derecho a existir» (2001: 10).

Así, en este estudio hemos prestado atención a la construcción de tres artefactos narrativos que confluyen en Lucía y el sexo: el guion de Medem, la metaficción de Lorenzo y, por último, la escritura virtual del espectador-rewriter, que se inaugura con los títulos de crédito y no se clausura con el final de la película, pues de él depende resolver el conflicto de la subtrama que queda abierta. 
Pero no es Lorenzo, sino Lucía, la lectora ficticia, quien sustenta el artificio. El bellísimo esfuerzo hermeneútico de la protagonista en la ficción también es reflejado por el espectador en su intento de comprender un discurso fílmico sumamente caótico. Al final del filme, Lucía se da cuenta de que todo lo que había proyectado solo era una mínima de las múltiples posibilidades de la historia. También Lorenzo, al llegar a Formentera para buscar a Lucía, no era consciente de que su historia inacabada se estaba construyendo en sí misma.

Medem elaboró esta historia apoyándose en múltiples versiones de la misma, de tal forma que incluso existen diferencias entre la película exhibida y el guion editado posteriormente. Así, parece que esta historia, lejos de concluirse, siempre puede reescribirse. De hecho, el 31 de octubre de 2015, Tristán Ulloa (Lorenzo) anunciaba en una entrevista que la secuela de Lucía y el sexo comenzaría a rodarse en próximas fechas. Sin embargo, este proyecto se paralizó meses después. ${ }^{13}$

Medem creó a Lucía porque se sentía culpable de haber matado a Ana en Los amantes del círculo polar. Se lo debía a Otto. El cine del donostiarra es famoso por el azar que lo envuelve. Más allá de la ficción está la vida, con su propio juego de azares. Antes de publicar el guion, cuando el director estaba montando Lucía y el sexo, murieron en un accidente su hermana Ana y su cuñada embarazada de un niño que iba a llamarse Otto. A ellos, desgraciadamente, dedica la edición de esta historia. La ventaja de la ficción, a diferencia de la realidad, es que cuando el cuento llega al final, no se acaba, se cae por un agujero y el cuento reaparece en mitad del cuento. Entonces, podemos cambiarle el rumbo...

\section{OBRAS CITADAS}

Abuín González, Anxo (2006), Escenarios del caos. Entre la hipertextualidad y la performance en la era electrónica, Valencia, Tirant lo Blanch.

Abuín González, Anxo (2012), El teatro en el cine, Madrid, Cátedra.

Angulo, Jesús y José Luis Rebordinos (2005), Contra la certeza: el cine de Julio Medem, San Sebastián, Filmoteca vasca/Festival de cine de Huesca.

Bolter, Trudy (2001), Figures de l'écrivain dans le cinéma américain. Itinéraires de la "voix baladeuse» [libro electrónico], Rennes, Presses universitaires de Rennes.

Buchanan, Judith (2013), «Image, Story, Desire: The Writer on Film», en Judith Buchanan (ed.), The Writer on film. Screening Literary Autorship [Libro electrónico], Houndmills, Basingstoke, Hampshire, Palgrave Macmillan, pp. 3-34.

Cartmell, Deborah (2013), «Becoming Jane in Screen Adaptations of Austen's Fiction», en Judith Buchanan (ed.), The Writer on film. Screening Literary Autorship [libro electrónico], Houndmills, Basingstoke, Hampshire, Palgrave Macmillan, pp. 151-163.

Catanzaro, Mary (2004), «Whose Story Is It?: Samuel Beckett's Malone Dies and the Voice of Self-Invention», en Michael J. Meyer (ed.), Literature and the Writer, Amsterdam, Rodopi.

Cercas, Javier y David Trueba (2003), Diálogos de Salamina: un paseo por el cine y la literatura, ed. Luis Alegre, Tusquets Editores y Plot Ediciones, Barcelona.

Dällenbach, Lucien (1991), El relato especular, Madrid, Visor.

${ }^{13}$ Disponible en: $<$ http://elpais.com/elpais/2015/10/27/icon/1445938083_207805.html>. 


\section{Clara Cobo Guijarro}

García, Carlos Javier (2005), «Metanovela y teoría de la novela: una conexión interrogativa de la autorreflexividad», Anthropos: huellas del conocimiento, CCVIII, pp. 65-70.

Genette, Gérard (2006), Metalepsis: de la figura a la ficción, Barcelona, Reverso.

Marcus, Laura (2013), «The Writer in Film: Autorship and Imagination», en Judith Buchanan (ed.), The Writer on film. Screening Literary Autorship [libro electrónico], Houndmills, Basingstoke, Hampshire, Palgrave Macmillan, pp. 35-49.

Medem, Julio (2001), Lucía y el sexo: guión cinematográfico original, Madrid, Ocho y Medio.

Peña Ardid, Carmen (1996), Literatura y cine. Una aproximación comparativa, Madrid, Cátedra.

Pérez Bowie, José Antonio (2008), Leer el cine. La teoría literaria en la teoría cinematográfica, Salamanca, Universidad de Salamanca.

Sánchez Noriega, José Luis (2004), Diccionario temático del cine, Madrid, Cátedra.

Sánchez Noriega, José Luis (2010), «De los literatos descontentos a los escritores cineastas y los relatos fílmico-literarios», Arbor: ciencia, pensamiento y cultura, CLXXXVI, 741, pp. 5-23, <http://arbor.revistas.csic.es/index.php/arbor/article/view/749/757>.

Sánchez Noriega, José Luis (2012), «Construcciones fílmicas de personajes históricos en el cine español (2000-2010)», Comunicación y sociedad, XXV, 2, pp. 57-84, $<$ http://dadun.unav.edu/handle/10171/27954> .

Shachar, Hila (2019), Screening the Author. The Literary Biopic [libro electrónico], Cham, Suiza, Palgrave Macmillan.

Thibaudeau, Pascale (2011), «Aporías narrativas en Lucía y el sexo de Julio Medem», Fotocinema: revista cientifica de cine y fotografia, II, pp. 19-35, < http://www.revistafotocinema.com/index.php?journal=fotocinema\&page $=$ article\&op=vi ew\&path $\% 5 \mathrm{~B} \% 5 \mathrm{D}=54>$.

Utrera Macías, Rafael (1985), Escritores y cinema en España: un acercamiento histórico, Madrid, Ediciones JC.

Wall, Geoffrey (2013), «Literary Biopics: a Literary Biographer's Perspective», en Judith Buchanan (ed.), The Writer on film. Screening Literary Autorship [libro electrónico], Houndmills, Basingstoke, Hampshire, Palgrave Macmillan, pp. 121-136. 